\title{
Personal attributes that influence the adequate management of hypertension and dyslipidemia in patients with type 2 diabetes. Results from the DIAB-CORE Cooperation
}

Ina-Maria Rückert ${ }^{*}$, Werner Maier², Andreas Mielck², Sabine Schipf ${ }^{3}$, Henry Völzke ${ }^{3}$, Alexander Kluttig ${ }^{4}$, Karin-Halina Greiser ${ }^{4,5}$, Klaus Berger ${ }^{6}$, Grit Müller ${ }^{6}$, Ute Ellert ${ }^{7}$, Hannelore Neuhauser ${ }^{7}$, Wolfgang Rathmann ${ }^{8}$, Teresa Tamayo ${ }^{8}$, Susanne Moebus ${ }^{9}$, Silke Andrich ${ }^{9}$ and Christa Meisinger ${ }^{1,10}$

\begin{abstract}
Background: Hypertension and dyslipidemia are often insufficiently controlled in persons with type 2 diabetes (T2D) in Germany. In the current study we evaluated individual characteristics that are assumed to influence the adequate treatment and control of hypertension and dyslipidemia and aimed to identify the patient group with the most urgent need for improved health care.

Methods: The analysis was based on the DIAB-CORE project in which cross-sectional data from five regional population-based studies and one nationwide German study, conducted between 1997 and 2006, were pooled. We compared the frequencies of socio-economic and lifestyle factors along with comorbidities in hypertensive participants with or without the blood pressure target of $<140 / 90 \mathrm{mmHg}$. Similar studies were also performed in participants with dyslipidemia with and without the target of total cholesterol/HDL cholesterol ratio $<5$. Furthermore, we compared participants who received antihypertensive/lipid lowering treatment with those who were untreated. Univariable and multivariable logistic regression models were used to assess the odds of potentially influential factors.

Results: We included 1287 participants with T2D of whom $n=1048$ had hypertension and $n=636$ had dyslipidemia. Uncontrolled blood pressure was associated with male sex, low body mass index (BMI), no history of myocardial infarction (MI) and study site. Uncontrolled blood lipid levels were associated with male sex, no history of $\mathrm{Ml}$ and study site. The odds of receiving no pharmacotherapy for hypertension were significantly greater in men, younger participants, those with $\mathrm{BMl}<30 \mathrm{~kg} / \mathrm{m} 2$ and those without previous $\mathrm{Ml}$ or stroke. Participants with dyslipidemia received lipid lowering medication less frequently if they were male and had not previously had an MI. The more recent studies HNR and CARLA had the greatest numbers of well controlled and treated participants.
\end{abstract}

Conclusion: In the DIAB-CORE study, the patient group with the greatest odds of uncontrolled co-morbidities and no pharmacotherapy was more likely comprised of younger men with low BMI and no history of cardiovascular disease.

Keywords: Type 2 Diabetes, Comorbidities, Hypertension, Dyslipidemia, Adherence to guidelines, Sex differences

\footnotetext{
* Correspondence: ina-maria.rueckert@helmholtz-muenchen.de

'Institute of Epidemiology II, Helmholtz Zentrum München, German Research

Center for Environmental Health $(\mathrm{GmbH})$ and German Center for Diabetes

Research (DZD e.V.), Ingolstädter Landstrasse 1, D-85764 München/

Neuherberg, Germany

Full list of author information is available at the end of the article
} 


\section{Introduction}

\section{Background}

Hypertension and dyslipidemia constitute major public health problems as they increase the risk of cardiovascular diseases (CVDs), especially in patients with concomitant type 2 diabetes (T2D) [1-4].

Nevertheless, several epidemiological studies indicate disappointing deficiencies in the detection and adequate treatment of hypertension and dyslipidemia in Germany with minimal improvement over the last decades [5-13]. About ten years ago, the South German site of the Monitoring Trends and Determinants in Cardiovascular Disease (MONICA) Study, the forerunner to the Cooperative Health Research in the Region of Augsburg (KORA) Study, revealed that the proportion of hypertensive participants with controlled hypertension $<140 /$ $90 \mathrm{mmHg}$ was only $7 \%$ in men and $13 \%$ in women [6]. An earlier analysis of regional differences using data of the two population-based German studies KORA and SHIP (Study of Health in Pomerania) with participants aged 25-74 years found that of all hypertensive participants, $8.4 \%$ in SHIP and $10.2 \%$ in KORA, were treated and well controlled. Recently, data of the German DIAB-CORE cooperation revealed that $64 \%$ of all participants with T2D and $49 \%$ of participants without T2D, aged 45-74 years, had untreated or insufficiently treated hypertension [8]. Despite the increased awareness of physicians and the public regarding the beneficial effects of blood pressure control on cardiovascular outcomes such as myocardial infarction and stroke ([5]), the data suggest that further barriers must exist that hinder optimal health care delivery.

\section{Objectives}

To our knowledge, no population-based study in Germany has so far dealt with characteristics of patients with T2D and hypertension and/or dyslipidemia who are not sufficiently treated for these serious conditions. In our study, we describe demographic, socio-economic and lifestyle factors in DIAB-CORE participants with diabetes and concomitant hypertension or dyslipidemia and analyse the factors associated with insufficient disease control and absent pharmacotherapy. We therefore aim to identify the group of patients with the most urgent need for intensified care.

\section{Methods}

\section{Study design and setting}

The DIAB-CORE Consortium consists of the following population-based studies (from north to south): the Study of Health in Pomerania (SHIP, Greifswald), the Dortmund Health Study (DHS, Dortmund), the Cardiovascular Disease, Living and Ageing (CARLA, Halle (Saale)) Study, the Heinz Nixdorf-Recall (HNR, Risk Factors, Evaluation of Coronary Calcification, and Lifestyle, Bochum, Essen, Mülheim a. d. Ruhr) Study, the Cooperative Health Research in the Region of Augsburg (KORA, Augsburg) Study, and the nationwide German National Health Interview and Examination Survey 1998 (GNHIES98), see Table 1.

All studies were conducted between 1997 and 2006 and used similar instruments, questionnaires and medical measurements to assess data. Detailed descriptions of study designs, samples and procedures are available elsewhere [14-20]. Ethical approval was obtained for

Table 1 Studies included in the pooled DIAB-CORE sample (45-74 years)

\begin{tabular}{|c|c|c|c|c|c|c|}
\hline \multirow[t]{2}{*}{ Study } & \multirow[t]{2}{*}{ Region } & \multirow[t]{2}{*}{ Study period } & \multirow[t]{2}{*}{ N (\%) } & \multirow{2}{*}{$\frac{\text { Age (years) }}{\text { mean }(\mathrm{SD})}$} & \multirow{2}{*}{$\begin{array}{l}\text { Hypertension } \\
\mathrm{N}(\%)\end{array}$} & \multirow{2}{*}{$\begin{array}{l}\text { Dyslipidemiz } \\
\mathrm{N}(\%)\end{array}$} \\
\hline & & & & & & \\
\hline \multirow[t]{3}{*}{$\mathrm{SHIP}^{\mathrm{a}}$} & North-east & $1997-2001$ & $251(19.5)$ & $62.8(7.5)$ & $215(85.7)$ & $143(57.0)$ \\
\hline & Germany & & & & & \\
\hline & (West Pomerania) & & & & & \\
\hline \multirow[t]{2}{*}{$D H S^{b}$} & West Germany & $2003-2004$ & $87(6.8)$ & $64.1(8.0)$ & $73(83.9)$ & - \\
\hline & (Dortmund) & & & & & \\
\hline \multirow[t]{2}{*}{ CARLA $^{c}$} & East Germany & $2002-2006$ & $174(13.5)$ & $63.5(7.3)$ & 155 (89.6) & $84(48.6)$ \\
\hline & (Halle) & & & & & \\
\hline$H_{N R}^{d}$ & $\begin{array}{l}\text { West Germany (Bochum, Essen, } \\
\text { Mülheim an der Ruhr) }\end{array}$ & $2000-2003$ & $350(27.2)$ & $63.0(7.2)$ & $263(78.5)$ & $174(52.1)$ \\
\hline \multirow[t]{2}{*}{ KORA $^{e}$} & South Germany & 1999-2001 & $146(11.3)$ & $63.3(6.7)$ & $114(78.6)$ & $80(55.9)$ \\
\hline & (Augsburg region) & & & & & \\
\hline GNHIES98 ${ }^{f}$ & Nationwide & 1997-1999 & $279(21.7)$ & $62.7(6.8)$ & $228(81.7)$ & 155 (59.6) \\
\hline Total & & 1997-2006 & 1287 & $63.1(7.2)$ & $1048(82.5)$ & $636(54.8)$ \\
\hline
\end{tabular}

${ }^{a}$ SHIP: Study of Health in Pomerania; ${ }^{b}$ DHS: Dortmund Health Study; ${ }^{c}$ CARLA: Cardiovascular Disease, Living and Ageing in Halle; ${ }^{d}$ HNR: Heinz Nixdorf-Recall; ${ }^{\mathrm{e}}$ KORA (Survey S4): Cooperative Health Research in the Region of Augsburg; ${ }^{\mathrm{f}} \mathrm{GNHIES98:} \mathrm{German} \mathrm{National} \mathrm{Health} \mathrm{Interview} \mathrm{and} \mathrm{Examination} \mathrm{Survey} 1998$. $\mathrm{BP}>=140 / 90 \mathrm{mmHg}$ or using anti-hypertensive medication

$\mathrm{TC} / \mathrm{HDL}>=5$ or using lipid-lowering medication. 
each study. Primary study data of interest were pooled and frequencies compared.

\section{Variables}

Age

Participants were classified in five age groups using five year intervals.

\section{Type 2 diabetes}

T2D was defined based on self-report or self-reported intake of oral anti-diabetic agents, insulin or a combination of both. Some studies lacked information on diabetes type. Thus, in order to exclude participants who probably had Type 1 diabetes, self-reported age at diagnosis of diabetes was used, and only those patients with an age at diagnosis of $>30$ years were included in the T2D group.

\section{Hypertension}

Hypertension was defined using the mean of the second and third blood pressure measurements (the first and second measurements in DHS) conducted at the study centres with systolic blood pressure $\geq 140$ and/or diastolic blood pressure $\geq 90 \mathrm{mmHg}$, or intake of antihypertensive medication in participants with physician's diagnosis of hypertension ("awareness"). Participants with hypertension were categorized into one of the following four subgroups: (1) aware (with physician' diagnosis) and controlled treated to target levels of $<140 /$ $90 \mathrm{mmHg}$, (2) aware and treated, but not reaching target blood pressure values of $<140 / 90 \mathrm{mmHg}$, i.e. uncontrolled treated, (3) aware, but not treated, (4) unaware of hypertension. Thus, "awareness" of hypertension applied to participants in categories 1, 2 and 3, "treatment" applied to those in categories 1 and 2 and "control" to those in category 1.

\section{Dyslipidemia}

Total cholesterol, high-density lipoprotein (HDL) cholesterol and low-density lipoprotein (LDL) cholesterol levels were measured from random blood samples. Dyslipidemia was defined analogously to hypertension using information on lipid-lowering medication intake, selfreported information on physician's diagnosis and a total cholesterol to HDL cholesterol ratio (TC/HDL) of $>=5$ $[21,22]$.

\section{Myocardial infarction (MI) and stroke}

Self-reported data on myocardial infarction and stroke ("Did you ever have a myocardial infarction/stroke, diagnosed by a physician?") was assessed identically in all studies.

\section{Anti-hypertensive medication}

All study participants were asked to bring original packaging of their medications used during the last seven days to the examination. The variable "anti-hypertensive medication" included any prescription of medication belonging to the ATC subgroups C02 (antihypertensives), C03 (diuretics), C04 (peripheral vasodilators), C07 (beta blocking agents), C08 (calcium channel blockers) and C09 (agents reacting on the renin-angiotensin system).

\section{Lipid-lowering medication}

Medications of the ATC subgroup C10 (lipid modifying agents) were included in the variable "lipid-lowering medication".

\section{Body mass index (BMI)}

The BMI $(\mathrm{kg} / \mathrm{m} 2)$ was calculated using standardized weight and height measurements.

\section{Smoking}

Two categories (current vs. ex- and never smoker) were defined to differentiate risk types. A current smoker reported smoking at least one cigarette per day. Persons who had reported that they had smoked at least one cigarette per day in the past but who quit smoking at least one year ago were defined as ex-smokers. Neversmokers were defined as those persons who had never smoked or smoked only occasionally ( $<1$ cigarette day).

\section{Physical inactivity}

In all studies, physical activity was assessed by self-report only. A threshold of less than $1 \mathrm{~h}$ of physical activity per week was determined for a high risk lifestyle. Assessment of activity was restricted to all kinds of exercise training but did not comprise low level exercise such as stepping stairs or walking, as this type of exercise was not assessed in all studies.

\section{Educational level}

In all studies, the participants were asked for their highest level of school qualification obtained. We classified educational level as a dichotomous variable contrasting low with medium or high level. According to the German school system, low educational level includes participants with up to 9 years of schooling. Medium educational level is equivalent to 10 years of schooling and high educational level to 12 or 13 years of schooling, which is required to enter a university.

\section{Income}

Information on monthly net household income as well as on household size was obtained from interviews. As the ages of household members were not available 
consistently across all studies, it was not possible to calculate the equivalent income according to the OECD equivalence scale. That is why the equivalent income was calculated according to the Luxembourg Income Study (income/household size) [23]. Pooling of income data was conducted by a regional approach, calculating the median income for each of the study centers separately. This approach allowed us to take into account overall income differences between the regions. For each study, we differentiated three income groups $(<60 \%$ of the study-specific median income, $\geq 60 \%$ up to $150 \%$, $>150 \%$ ) and pooled these groups across the six studies.

\section{Participants}

The pooled data set included 1,287 participants with T2D aged 45 to 74 years. In the nationwide survey GNHIES98, 3\% non-German citizens were included, KORA, SHIP and CARLA focused on participants of German nationality, and the other studies collected information on birthplace only. Two-stage cluster sampling or stratified random sampling were used. Overall response ranged between 56 and 69\%.

The hypertension sub-analysis included 1,048 hypertensive participants. $\mathrm{N}=17$ participants were excluded due to missing information on: study blood pressure measurement $(n=3)$, physician's diagnosis of hypertension $(n=3)$, and/or medication intake $(n=14)$.

The dyslipidemia sub-analysis included 636 participants with dyslipidemia according to the definition specified above. $\mathrm{N}=126$ participants had to be excluded due to missing information on laboratory measurements $(n=32)$, physician's diagnosis of dyslipidemia ( $n=90$, all participants of DHS and 3 of HNR), and/or medication intake $(n=14) . N=16$ participants were not included in either one of the two sub-analyses.

\section{Statistical analyses}

T2D participants with hypertension, with or without the blood pressure target of $<140 / 90 \mathrm{mmHg}$, and T2D participants with dyslipidemia with or without the target of total cholesterol/HDL cholesterol $<5$, as well as T2D participants with or without treatment were compared with respect to their lifestyle factors, cardiovascular burden, clinical measurements and medications. Continuous variables were characterized by means and standard deviations (SD), categorical variables were described as percentages. Differences between groups were calculated using t-tests and Wilcoxon tests (continuous variables) or chi-square tests and univariable logistic regression models (categorical variables). At first, univariable logistic regression models were programmed to identify factors associated with blood pressure, lipid ratio or medication intake. In a second step, variables found to be significantly associated with the respective outcome were included in multivariable models to examine adjusted effects.

The goodness-of-fit of adjusted models was assessed by the c-value, and the Hosmer-Lemeshow test. The c-value describes the area under the ROC-curve, ranging from 0.5 (random correlations) to 1.0 (perfect fit). In epidemiologic studies, values between 0.6 and 0.8 are usually regarded as satisfactory. The Hosmer-Lemeshow test compares observed and predicted values with each other. If there is no significant difference (at the significance level of 0.05) the model is characterized as being appropriate.

A two-sided alpha level of 0.05 was chosen as criterion for statistical significance. All analyses were carried out using SAS, version 9.2 (SAS Institute Inc., Cary, NC, USA).

\section{Results}

Participants

Of 1,287 T2D participants aged 45-74 years, $\mathrm{n}=1,048$ (82.5\%) had hypertension and $n=636$ (54.8\%) had dyslipidemia. $\mathrm{N}=530(41.2 \%)$ had both conditions and were included in both sub-analyses.

The frequency of hypertension in persons with T2D differed slightly between studies, ranging from $78.5 \%$ in HNR to $89.6 \%$ in CARLA. Likewise, the number of participants with dyslipidemia ranged from $48.6 \%$ in CARLA to $59.6 \%$ in GNHIES98. The mean age was 63.1 years (Std. 7.2 years), and was very similar across all studies (Table 1). In total, $45.1 \%$ of participants were female, ranging from $40.0 \%$ in HNR to $49.8 \%$ in GNHIES98. Within the group of hypertensive participants, $46.3 \%$ were female, among participants with dyslipidemia, 43.1\% were female.

\section{Descriptive data}

Of 1,048 participants with T2D and hypertension, $\mathrm{n}=240(22.9 \%)$ had controlled blood pressure of $<140$ / $90 \mathrm{mmHg}$, and $\mathrm{n}=808$ (77.1\%) were uncontrolled. Dyslipidemia was treated to TC/HDL ratio $<5$ in $143(22.5 \%)$ of 636 T2D participants and uncontrolled dyslipidemia was observed in 493 (77.5\%) T2D participants (Figure 1).

Frequencies of associated variables, stratified by participants with and without controlled hypertension and with and without controlled dyslipidemia, respectively, are shown in Table 2. Frequencies of participant characteristics, stratified by those treated for hypertension or dyslipidemia, respectively, and those not treated for these diseases are shown in Table 3.

\section{Focus on differences between women and men}

Systolic blood pressure (SBP) increased with age in participants with T2D, while diastolic blood pressure (DBP) decreased. Both measurements were consistently lower 


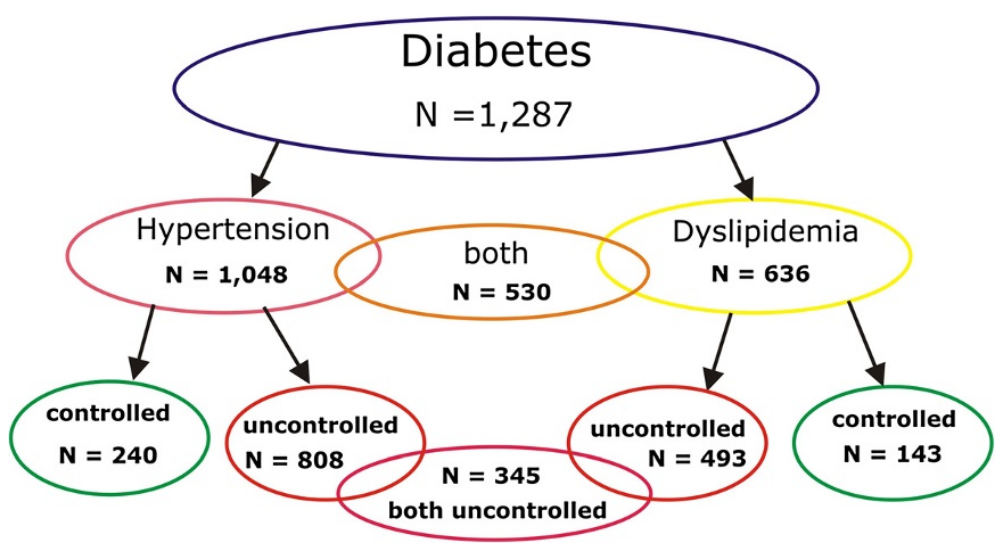

Figure 1 Frequencies of controlled and uncontrolled hypertension and dyslipidemia.

in women of all age groups than in their male counterparts (mean SBP in women: $149.8 \mathrm{mmHg}$ (SD 20.8) vs. $154.4 \mathrm{mmHg}$ (20.6) in men, mean DBP 83.2 (11.1) and 86.6 (11.2) in women and men, respectively) (Figure 2). Whilst men were more often free from hypertension $(19.3 \%$ vs. $15.2 \%)$, women were significantly more often diagnosed and well controlled if affected: $25.0 \%$ of all women had controlled hypertension, compared to $13.9 \%$ in men, $43.5 \%$ were treated but did not achieve goal levels (compared to $38.8 \%$ in men), $5.9 \%$ were not treated even though they had a physician's diagnosis of hypertension (compared to $7.3 \%$ in men), and $10.3 \%$ had unknown hypertension (compared to $20.6 \%$ in men) (see Figure 3).

Total cholesterol and HDL-cholesterol were higher in women than in men $(232.2 \mathrm{mg} / \mathrm{dl}$ (SD 48.8$)$ vs. $216.4 \mathrm{mg} / \mathrm{dl}$ (48.0) and 53.9 (16.6) vs. $46.3(14.0)$ ) - albeit, $48.7 \%$ of women and $35.1 \%$ of men had less than 50 or less than $40 \mathrm{mg} / \mathrm{dl}$ HDL respectively. However, the TC/HDL ratio was lower in women $(4.7$ (1.7) vs. 5.0 (1.7)).

More women than men were not affected with dyslipidemia as defined by a TC/HDL ratio $<5(47.5 \%$ vs. 43.4\%), 14.9\% were treated and well-controlled (vs. 10.2\% in men), $7.9 \%$ were treated but did not reach goal values (compared to $6.7 \%$ in men), $16.3 \%$ were not treated despite of a physician's diagnosis (compared to $17.8 \%$ in men) and $13.4 \%$ had unknown dyslipidemia (compared to $21.9 \%$ in men) (see Figure 3).

\section{Factors associated with uncontrolled hypertension or uncontrolled dyslipidemia}

Univariable logistic regression models yielded significant associations of uncontrolled hypertension with sex (OR for men: $2.01,95 \%$ CI $1.50-2.69), \mathrm{BMI}<30(\mathrm{OR}=1.89$, 95\% CI 1.40-2.55), and study. Age in five groups was not significantly associated but displayed a steady tendency towards having the greatest odds in the second oldest group (65-69 years) compared to the youngest group (45-54 years). With GNHIES98 as the reference study, HNR had the smallest odds of uncontrolled hypertension $(\mathrm{OR}=0.32$, 95\% CI $0.20-0.50)$, followed by CARLA $(\mathrm{OR}=0.47,95 \%$ CI $0.28-0.79)$ and KORA (OR $=0.52$, 95\% CI 0.30-0.91). Multivariable analysis with these significant variables (i.e. sex, BMI and study) showed consistent results as well as the associated factor "no previous MI' which reached statistical significance $(\mathrm{OR}=$ 1.70, 95\% CI 1.06-2.70). A model including only sex, BMI and study had a c-value of 0.68 and a nonsignificant Hosmer-Lemeshow test $(\mathrm{p}=0.78)$.

Uncontrolled dyslipidemia was significantly associated with sex (OR for men: 1.82, 95\% CI 1.25-2.65), no previous $\mathrm{MI}(\mathrm{OR}=2.22,95 \% \mathrm{CI} 1.37-3.59)$ and study (OR for CARLA: $0.24,95 \%$ CI $0.13-0.46$ and HNR 0.41, 95\% CI 0.23-0.74, GNHIES98 as reference). Again, age was not significantly associated, but showed some tendency, albeit in the other direction, with the youngest age group displaying the greatest odds of uncontrolled dyslipidemia (70-74 years as reference). Multivariable analysis with sex, MI, and study generated consistent odds. A model including only these variables had a c-value of 0.69 and a non-significant Hosmer-Lemeshow test result $(\mathrm{p}=0.96)$. Smoking, physical activity, educational level and income were not significantly associated with either control of hypertension or dyslipidemia (Table 4).

\section{Factors associated with no pharmacotherapy for hypertension or dyslipidemia}

Using univariable regression models, we found significant odds of non-use of anti-hypertensive medication in younger study participants (OR for 45-54 years: 2.54, 95\% CI 1.54-4.20, OR for 55-59 years: $2.15,95 \%$ CI 1.31-3.53, 70-74 years as reference), males $(\mathrm{OR}=2.11$, 95\% CI 1.54-2.87), current smokers (OR: $1.80,95 \%$ CI 
Table 2 Study characteristics of participants with T2D in DIAB-CORE, age range 45-74

\begin{tabular}{|c|c|c|c|c|}
\hline & $\begin{array}{l}\text { Controlled hypertension } \\
\leq 140 / 90 \mathrm{mmHg} \\
\end{array}$ & $\begin{array}{l}\text { Uncontrolled hypertension } \\
>=140 / 90 \mathrm{mmHg}\end{array}$ & $\begin{array}{l}\text { Controlled dyslipidemia } \\
\text { TC/HDL ratio }<5\end{array}$ & $\begin{array}{l}\text { Uncontrolled dyslipidemia } \\
\text { TC/HDL ratio > =5 } \\
\end{array}$ \\
\hline & $\mathrm{n}=\mathbf{2 4 0}$ & $\mathrm{n}=808$ & $n=143$ & $n=493$ \\
\hline Age (years) & $62.8(7.2)$ & $63.8(6.9)$ & $63.8(6.7)$ & $62.4(7.3)$ \\
\hline Women (\%) & 59.6 & 42.3 & 54.6 & 39.8 \\
\hline BMI (kg/m2) & $32.4(5.9)$ & $30.7(5.0)$ & $30.6(5.1)$ & $31.2(5.2)$ \\
\hline $\mathrm{BMI}>=30 \mathrm{~kg} / \mathrm{m} 2(\%)$ & 64.2 & 48.6 & 51.1 & 50.7 \\
\hline Current smoking (\%) & 15.7 & 14.2 & 13.4 & 19.9 \\
\hline Low physical activity (\%) & 71.2 & 73.5 & 68.1 & 75.0 \\
\hline Low income (\%) & 17.8 & 17.0 & 17.4 & 18.5 \\
\hline Low education (\%) & 78.3 & 78.7 & 80.9 & 79.6 \\
\hline Diabetes duration (years) & $8.3(7.7)$ & $8.9(7.5)$ & $10.1(7.9)$ & $7.9(7.0)$ \\
\hline \multicolumn{5}{|l|}{ Diabetes treatment (\%) } \\
\hline Diet only or no treatment (\%) & 20.0 & 21.9 & 20.3 & 21.5 \\
\hline OAD only (\%) & 47.5 & 51.2 & 42.7 & 53.7 \\
\hline Insulin only (\%) & 19.6 & 17.1 & 19.6 & 13.4 \\
\hline OAD and Insulin (\%) & 12.9 & 9.8 & 17.5 & 11.4 \\
\hline \multicolumn{5}{|l|}{ Blood pressure $(\mathrm{mm} \mathrm{Hg})$} \\
\hline Systolic BP (mm Hg) & $126.3(10.4)$ & $160.0(16.4)$ & $148.1(23.9)$ & $147.6(21.6)$ \\
\hline Diastolic BP (mm Hg) & $75.7(7.9)$ & $87.8(10.7)$ & $80.6(11.1)$ & $84.1(11.4)$ \\
\hline Hypertension (\%) & 100.0 & 100.0 & 85.9 & 82.8 \\
\hline current BP > =140/90 (\%) & 0.0 & 100.0 & 59.9 & 65.9 \\
\hline \multicolumn{5}{|l|}{ Cholesterol (mg/dl) } \\
\hline $\mathrm{TC}(\mathrm{mg} / \mathrm{dl})$ & $218.4(46.2)$ & $226.8(50.3)$ & $199.0(37.0)$ & $244.5(53.6)$ \\
\hline LDL (mg/dl) & $132.3(37.9)$ & $138.5(39.9)$ & $114.4(32.4)$ & $153.9(42.1)$ \\
\hline $\mathrm{HDL}(\mathrm{mg} / \mathrm{dl})$ & $50.2(15.7)$ & $50.0(16.0)$ & $56.3(15.5)$ & $39.1(8.4)$ \\
\hline Dyslipidemia (\%) & 53.8 & 55.9 & 100.0 & 100.0 \\
\hline current TC/HDL ratio > = $5(\%)$ & 37.1 & 43.0 & 0.0 & 100.0 \\
\hline Myocardial infarction (\%) & 13.4 & 9.4 & 22.7 & 11.7 \\
\hline Stroke (\%) & 9.2 & 7.4 & 7.0 & 7.7 \\
\hline
\end{tabular}

Numbers are means (SD) or percentages and relate to the number of subjects available for analysis.

$B M I$ : body mass index, OAD: oral anti-diabetic medication, $T C$ : total cholesterol, $L D L$ : low-density lipoprotein, $H D L$ : high-density lipoprotein, $C V D$ : cardiovascular disease, $B P$ : blood pressure.

$\mathrm{BP}>=140 / 90 \mathrm{mmHg}$ or using anti-hypertensive medication.

$\mathrm{TC} / \mathrm{HDL}$ ratio $>=5$ or using lipid-lowering medication.

Test of the difference between participants with controlled hypertension and those with uncontrolled hypertension, $\mathrm{p}<0.05$.

Test of the difference between participants with controlled dyslipidemia and those with uncontrolled dyslipidemia, $p<0.05$.

1.22-2.64) and participants with $\mathrm{BMI}<30(\mathrm{OR}=2.06$, 95\% CI 1.52-2.79). Moreover, no previous MI $(\mathrm{OR}=3.75$, 95\% CI 1.79-7.82), no previous stroke (OR $=3.12,95 \%$ CI 1.42-6.88) and study (OR for CARLA: 0.42, 95\% CI 0.24-0.71, OR for HNR: 0.60, 95\% CI 0.40-0.92, GNHIES98 as reference) were significantly associated with untreated hypertension. In multivariable models adjusted for age, sex, BMI, MI, stroke, and study, the odds remained significant, except for smoking. A model including only these significant variables was characterized by a c-value of 0.71 and a non-significant HosmerLemeshow test result $(p=0.46)$.
Non-use of lipid lowering medication in participants with dyslipidemia was univariably associated with male sex $(\mathrm{OR}=1.75,95 \% \mathrm{CI} 1.27-2.43)$ and no $\mathrm{MI}(\mathrm{OR}=3.16$, 95\% CI 1.99-5.01). Multivariable analysis adjusted for these two variables yielded additionally significant odds for no concomitant hypertension $(\mathrm{OR}=1.71$, 95\% CI 1.06$2.78)$, physical inactivity $(\mathrm{OR}=1.49,95 \% \mathrm{CI} 1.03-2.17)$ and the CARLA study $(\mathrm{OR}=0.56,95 \% \mathrm{CI} 0.32-0.98)$. A model including only sex and MI had a c-value of 0.64 and a non-significant Hosmer-Lemeshow test $(p=0.62)$. Neither education nor income were associated with treatment of hypertension or dyslipidemia (Table 5). 
Table 3 Characteristics of diabetic participants with and without medical treatment for hypertension or dyslipidemia

\begin{tabular}{|c|c|c|c|c|}
\hline & $\begin{array}{l}\text { Anti-hypertensive } \\
\text { medication }\end{array}$ & $\begin{array}{l}\text { No anti-hypertensive } \\
\text { medication }\end{array}$ & $\begin{array}{l}\text { Lipid lowering } \\
\text { medication }\end{array}$ & $\begin{array}{l}\text { No lipid lowering } \\
\text { medication }\end{array}$ \\
\hline & $n=822$ & $n=226$ & $n=240$ & $n=396$ \\
\hline Age (years) & $64.1(6.8)$ & $61.8(7.3)$ & $63.5(6.5)$ & $62.2(7.5)$ \\
\hline Women (\%) & 50.1 & 32.3 & 51.7 & 37.9 \\
\hline BMI (kg/m2) & $31.5(5.4)$ & $29.5(4.2)$ & $30.8(5.1)$ & $31.2(5.2)$ \\
\hline $\mathrm{BMI}>=30 \mathrm{~kg} / \mathrm{m} 2(\%)$ & 56.0 & 38.2 & 51.3 & 50.5 \\
\hline Current smoking (\%) & 12.8 & 20.9 & 14.8 & 20.6 \\
\hline Low physical activity (\%) & 73.4 & 71.4 & 69.1 & 76.0 \\
\hline Low income (\%) & 16.8 & 18.4 & 18.3 & 18.2 \\
\hline Low education (\%) & 79.4 & 75.7 & 81.3 & 79.0 \\
\hline Diabetes duration (years) & $9.0(7.6)$ & $7.8(7.0)$ & $9.2(7.3)$ & $7.9(7.2)$ \\
\hline \multicolumn{5}{|l|}{ Diabetes treatment (\%) } \\
\hline Diet only or no treatment (\%) & 19.6 & 28.3 & 18.3 & 23.0 \\
\hline OAD only (\%) & 49.5 & 53.5 & 46.3 & 54.2 \\
\hline Insulin only (\%) & 19.1 & 12.4 & 19.6 & 11.9 \\
\hline OAD and Insulin (\%) & 11.8 & 5.8 & 15.8 & 10.9 \\
\hline \multicolumn{5}{|l|}{ Blood pressure (mm Hg) } \\
\hline Systolic BP (mm Hg) & $150.4(21.6)$ & $159.0(16.0)$ & $147.3(23.3)$ & $148.0(21.4)$ \\
\hline Diastolic BP (mm Hg) & $83.7(11.3)$ & $90.0(9.7)$ & $80.9(11.2)$ & $84.8(11.4)$ \\
\hline Hypertension (\%) & 100 & 100 & 87.0 & 81.3 \\
\hline current BP > = 140/90 (\%) & 70.8 & $\begin{array}{l}100 \text { (due to definition } \\
\text { of hypertension) }\end{array}$ & 60.7 & 66.9 \\
\hline \multicolumn{5}{|l|}{ Cholesterol (mg/dl) } \\
\hline $\mathrm{TC}(\mathrm{mg} / \mathrm{dl})$ & $224.9(51.2)$ & $224.6(43.0)$ & $215.6(50.2)$ & $245.5(52.8)$ \\
\hline LDL (mg/dl) & $136.8(40.1)$ & $138.0(37.2)$ & $126.9(42.3)$ & $155.3(40.5)$ \\
\hline $\mathrm{HDL}(\mathrm{mg} / \mathrm{dl})$ & $49.9(15.8)$ & $50.3(16.3)$ & $48.8(15.8)$ & $39.4(8.5)$ \\
\hline Dyslipidemia (\%) & 56.1 & 52.9 & 100 & 100 \\
\hline current $\mathrm{TC} / \mathrm{HDL}$ ratio $>=5(\%)$ & 40.9 & 44.6 & 40.4 & $\begin{array}{l}100 \text { (due to definition } \\
\text { of dyslipidemia) }\end{array}$ \\
\hline Myocardial infarction (\%) & 12.1 & 3.6 & 23.1 & 8.7 \\
\hline Stroke $(\%)$ & 9.1 & 3.1 & 8.0 & 7.3 \\
\hline
\end{tabular}

Numbers are means (SD) or percentages and relate to the number of subjects available for analysis.

$B M I$ : body mass index, OAD: oral anti-diabetic medication, $T C$ : total cholesterol, $L D L$ : low-density lipoprotein, $H D L$ : high-density lipoprotein, $C V D$ : cardiovascular disease, $B P$ : blood pressure.

$\mathrm{BP}>=140 / 90 \mathrm{mmHg}$ or using anti-hypertensive medication.

$\mathrm{TC} / \mathrm{HDL}$ ratio $>=5$ or using lipid-lowering medication.

Test of the difference between participants with antihypertensive medication and those without such medication, $\mathrm{p}<0.05$.

Test of the difference between participants with lipid lowering medication and those without such medication, $p<0.05$

\section{Discussion}

\section{Key results}

Uncontrolled blood pressure in T2D participants with (diagnosed or unrecognized) hypertension was associated with male sex, BMI $<30 \mathrm{~kg} / \mathrm{m} 2$, no previous MI, and study site. Similarly, uncontrolled blood lipid levels in T2D participants with dyslipidemia (diagnosed or unrecognized) were more frequent in men, those who had not suffered $\mathrm{MI}$ and attendees of the older DIAB-CORE studies.

Lack of treatment for hypertension was related to younger age, male sex, smoking, $\mathrm{BMI}<30$, no history of
MI or stroke, and study site. Male T2D participants without concomitant hypertension and who had not suffered MI had significantly greater odds of untreated dyslipidemia than other participants in DIAB-CORE.

Socioeconomic features such as educational level and income were not significantly associated with either disease control or pharmacotherapy; lifestyle factors were only associated in some models.

On the one hand, the results of our analyses indicate that the vast majority of patients with T2D in Germany are not adequately treated for hypertension and/or 

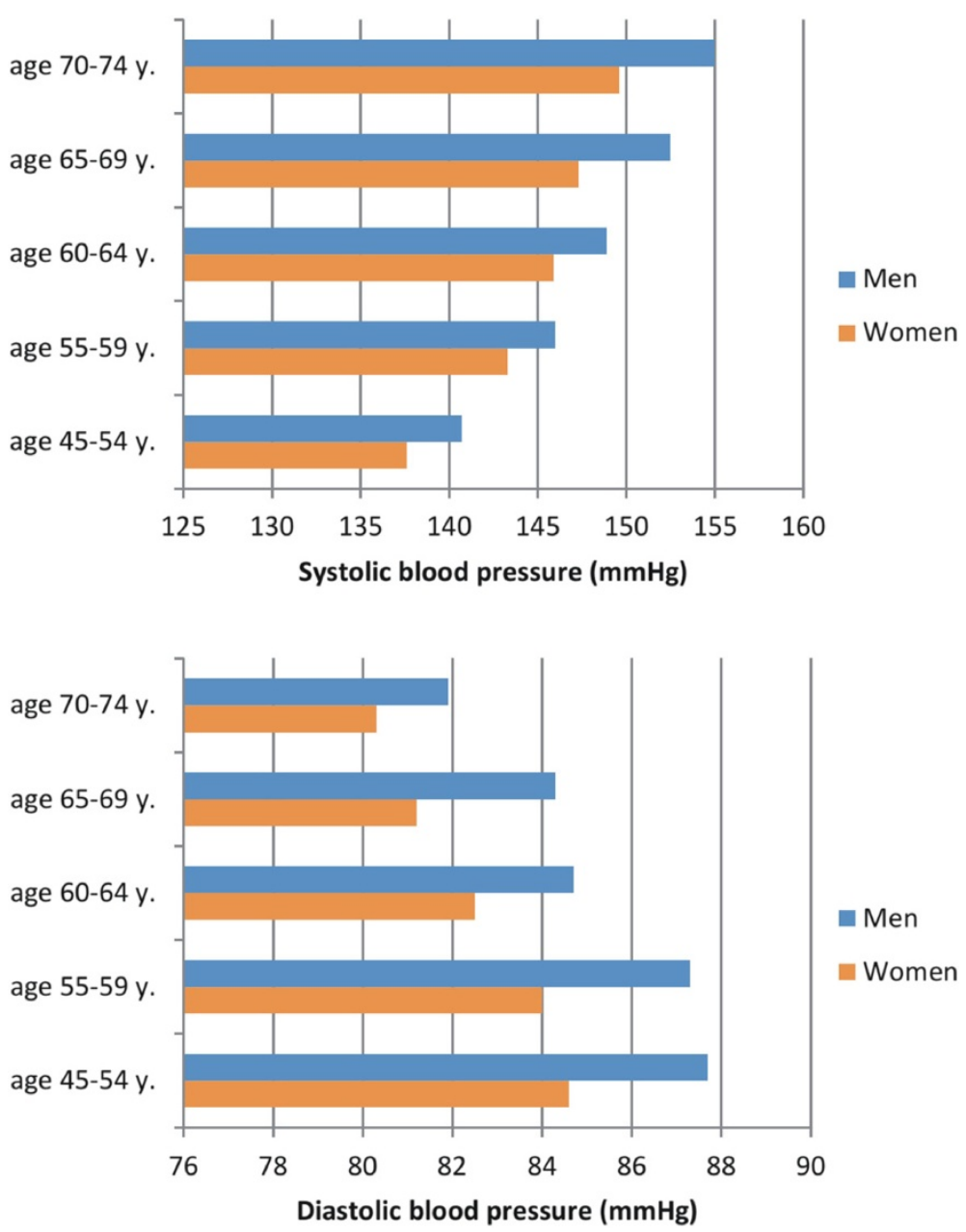

Figure 2 Systolic and diastolic blood pressure in all women and men with T2D stratified by age groups.

dyslipidemia, even though these conditions have been found to considerably increase the risk of co-morbidities and complications such as MI, stroke, nephropathy and retinopathy.

On the other hand, we confirmed the presumption that patients with additional risk factors, such as advanced age, previous MI, previous stroke or obesity are treated more often for hypertension and dyslipidemia and (apart from those with older age) more frequently achieve adequate blood pressure and lipid target levels. The difference between female and male participants was pronounced and consistent over all sub-analyses.

\section{Strengths and limitations}

The essential strength of our study is the large population-based sample drawn from the general German population, aged 45 to 74 years, and the fact that both, laboratory measurements and information on medication intake were available.
Differences in the frequencies of hypertension and dyslipidemia between studies were probably due to the relatively small numbers of affected participants within the individual studies and analyses. Due to the pooling process, only similarly collected and coded data of all six studies could be used and the least common denominator had to be found. Therefore, the definition of diabetes was based on self-report of physician's diagnosis and treatment with anti-diabetic agents rather than on clinical diagnosis and medical records. Blood pressure was calculated using the mean of the second and third measurements in all studies except for DHS, where only two measurements were performed and used to calculate the mean.

Moreover, measurements of blood pressure and lipids based on a single testing opportunity provide evidence for the respective condition, but are not equal to a clinical diagnosis with repeated measurements. We cannot exclude cases of 'white coat hypertension', i.e. elevated blood pressure caused by the excitement of the unfamiliar situation. 

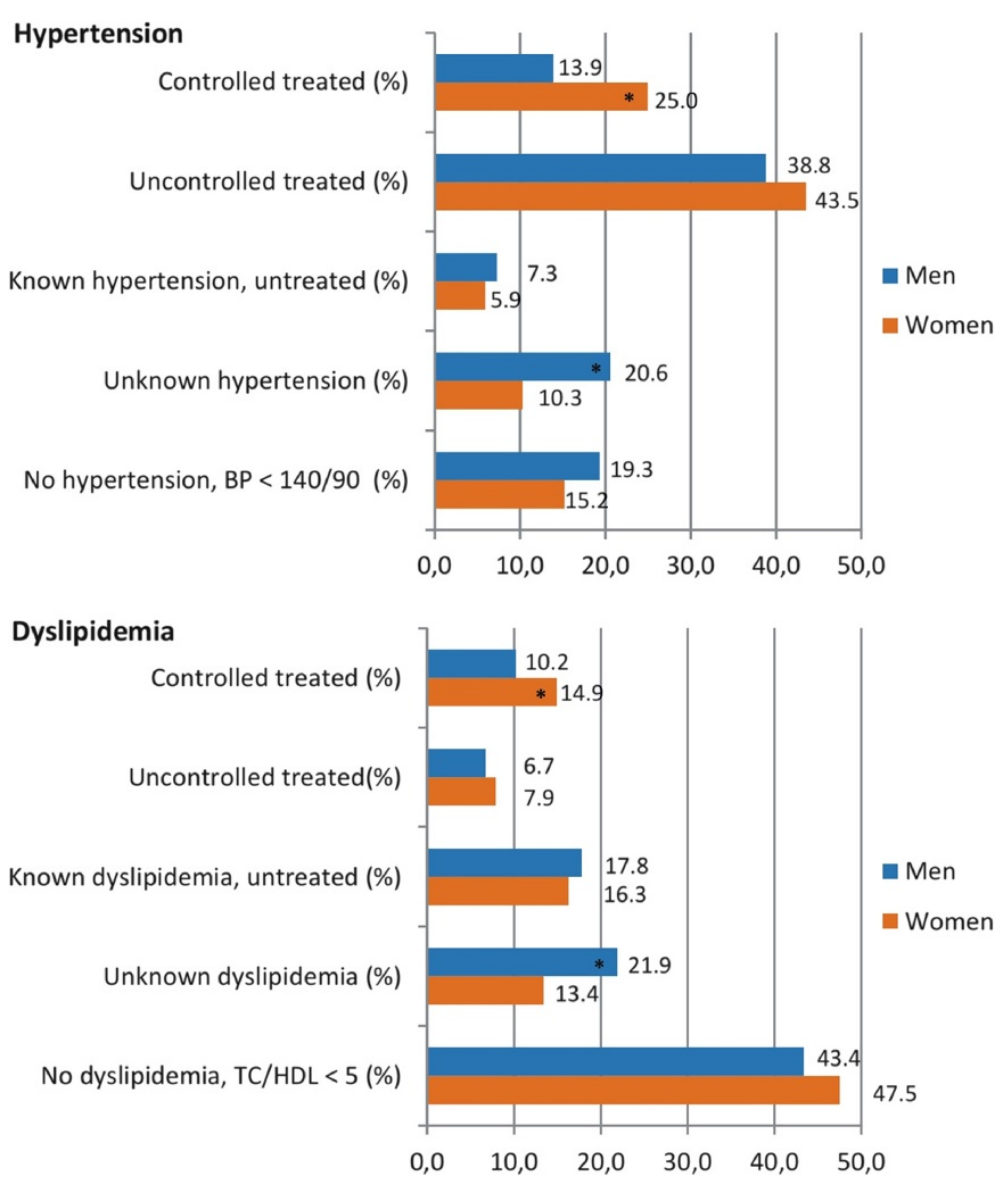

Figure 3 Percentages of all participants with T2D - without hypertension or without dyslipidemia, with controlled, uncontrolled treated, known, but not treated, and unrecognized disease status stratified by sex.

Due to compliance issues, women might have reported their medication intake more reliably than men, thus pharmacotherapy in men could have been underestimated and consequently, sex-specific differences overestimated in these analyses.

\section{Generalization}

Patient-centered studies in Germany and other countries have so far examined awareness, treatment, control and factors associated with insufficient control of comorbidities in patients with and without diabetes. A systematic review by McLean et al. from 2008, which included 26 studies from different countries with 66,833 diabetes patients with co-morbid hypertension, concluded that $83 \%$ (range $32-100 \%$ ) of patients were treated, yet only about 29\% (range 5-59\%) had their blood pressure controlled to $<140 / 90 \mathrm{mmHg}$. The proportions of treatment to control were similar and thus equally insufficient between studies and countries. Unfortunately, the authors did not report person-related factors associated with disease control [24].

\section{Differences by gender}

There are very few studies that have reported factors associated with cardiovascular disease control in patients with diabetes, as opposed to adults in general, irrespective of diabetes status. However, a number of recent studies that focused on gender differences [25-30] found that female patients with diabetes had a worse cardiovascular risk profile and were less controlled compared to their male counterparts. Our study confirmed these results in part; women in DIAB-CORE had higher total cholesterol values than men. However, since HDL-cholesterol values were also higher, the TC/HDL ratio was lower and thus more beneficial in women. In all studies [25-30], blood pressure was higher in women, especially in patients with cardiovascular disease. Although this sex difference was abrogated in some analyses after adjustment for associated variables $[27,28]$. There was either no sex difference in the amount of antihypertensive and lipid-lowering medication, or women took more medication, which is in agreement with our study. Furthermore, our results indicate that men are about twice as often unaware of their hypertension and dyslipidemia as women, which is well in line 
Table 4 Factors associated with high BP* and cholesterol^ in diabetic study participants with concomitant (diagnosed or unrecognized) hypertension or dyslipidemia

\begin{tabular}{|c|c|c|c|c|c|c|c|c|}
\hline & \multicolumn{4}{|c|}{ Hypertension } & \multicolumn{4}{|c|}{ Dyslipidemia } \\
\hline & \multirow[t]{2}{*}{$\mathbf{N}$} & \multirow{2}{*}{$\frac{B P>=140 / 90}{n(\%)}$} & \multirow[t]{2}{*}{ Unadjusted } & \multirow{2}{*}{$\begin{array}{l}\text { Adjusted for Sex, } \\
\text { BMI, Study }\end{array}$} & \multirow{2}{*}{$\mathrm{N}$} & \multirow{2}{*}{$\frac{\mathrm{TC} / \mathrm{HDL} \text { ratio }>=5}{\mathrm{n}(\%)}$} & \multirow[t]{2}{*}{ Unadjusted } & \multirow{2}{*}{$\begin{array}{l}\text { Adjusted for Sex } \\
\text { MI, Study }\end{array}$} \\
\hline & & & & & & & & \\
\hline & 1048 & $808(77.1)$ & OR $(95 \% \mathrm{Cl})$ & OR $(95 \% \mathrm{Cl})$ & 636 & $493(77.5)$ & OR $(95 \% \mathrm{Cl})$ & OR $(95 \% \mathrm{Cl})$ \\
\hline \multicolumn{9}{|l|}{ Age in years } \\
\hline 70-74 & 257 & 202 (78.6) & $1.45(0.90-2.35)$ & $1.48(0.90-2.46)$ & 134 & $101(75.4)$ & Reference & Reference \\
\hline $65-69$ & 252 & $201(79.8)$ & $1.56(0.96-2.54)$ & $1.70(1.02-2.84)$ & 146 & 105 (71.9) & $0.84(0.49-1.43)$ & $0.83(0.47-1.45)$ \\
\hline $60-64$ & 254 & $196(77.2)$ & $1.34(0.83-2.15)$ & $1.33(0.81-2.19)$ & 157 & $126(80.3)$ & $1.33(0.76-2.32)$ & $1.28(0.71-2.30)$ \\
\hline $55-59$ & 151 & $113(74.8)$ & 1.18 (0.70-1.99) & $1.13(0.65-1.96)$ & 98 & 79 (80.6) & $1.36(0.72-2.57)$ & $1.23(0.63-2.40)$ \\
\hline $45-54$ & 134 & 96 (71.6) & Reference & Reference & 101 & $82(81.2)$ & $1.41(0.75-2.66)$ & $1.33(0.70-2.59)$ \\
\hline \multicolumn{9}{|l|}{ Sex } \\
\hline Male & 563 & $466(82.8)$ & $2.01(1.50-2.69)$ & $2.00(1.47-2.72)$ & 362 & 297 (82.0) & $1.82(1.25-2.65)$ & $2.23(1.49-3.33)$ \\
\hline Female & 485 & $342(70.5)$ & Reference & Reference & 274 & 196 (71.5) & Reference & Reference \\
\hline \multicolumn{9}{|l|}{ BMI } \\
\hline$>=30$ & 546 & $392(71.8)$ & Reference & Reference & 322 & $249(77.3)$ & Reference & Reference \\
\hline$<30$ & 500 & $414(82.8)$ & $1.89(1.40-2.55)$ & $1.75(1.28-2.40)$ & 312 & $242(77.6)$ & $1.01(0.70-1.47)$ & $0.82(0.55-1.23)$ \\
\hline \multicolumn{9}{|c|}{ Currently smoking } \\
\hline Yes & 150 & $113(75.3)$ & Reference & Reference & 115 & $96(83.5)$ & $1.61(0.94-2.74)$ & $1.56(0.88-2.75)$ \\
\hline No & 880 & $682(77.5)$ & $1.13(0.75-1.69)$ & $1.30(0.84-1.99)$ & 510 & $387(75.9)$ & Reference & Reference \\
\hline \multicolumn{9}{|l|}{ Physical inactivity } \\
\hline Yes & 757 & $589(77.8)$ & $1.13(0.82-1.55)$ & $0.98(0.70-1.38)$ & 461 & $365(79.2)$ & $1.40(0.93-2.11)$ & $1.27(0.82-1.98)$ \\
\hline No & 280 & $212(75.7)$ & Reference & Reference & 167 & $122(73.1)$ & Reference & Reference \\
\hline \multicolumn{9}{|l|}{ School education } \\
\hline Low & 811 & $627(77.3)$ & $1.02(0.72-1.46)$ & $1.07(0.73-1.55)$ & 499 & $385(77.2)$ & Reference & Reference \\
\hline High and middle & 221 & $170(76.9)$ & Reference & Reference & 126 & 99 (78.6) & $1.09(0.68-1.74)$ & $1.00(0.60-1.64)$ \\
\hline \multicolumn{9}{|l|}{ Income } \\
\hline Low & 162 & $124(76.5)$ & Reference & Reference & 104 & $81(77.9)$ & Reference & Reference \\
\hline Middle & 674 & $521(77.3)$ & $1.04(0.70-1.57)$ & $0.86(0.56-1.33)$ & 405 & $306(75.6)$ & $0.88(0.52-1.47)$ & $0.84(0.49-1.45)$ \\
\hline High & 109 & $86(78.9)$ & $1.15(0.64-2.06)$ & $0.98(0.53-1.83)$ & 62 & $52(83.9)$ & $1.48(0.65-3.35)$ & $1.12(0.47-2.65)$ \\
\hline \multicolumn{9}{|c|}{ Myocardial infarction } \\
\hline Yes & 107 & $75(70.1)$ & Reference & Reference & 89 & $57(64.0)$ & Reference & Reference \\
\hline No & 934 & 727 (77.8) & $1.50(0.96-2.33)$ & $1.70(1.06-2.70)$ & 540 & $431(79.8)$ & $2.22(1.37-3.59)$ & $2.81(1.69-4.69)$ \\
\hline \multicolumn{9}{|l|}{ Stroke } \\
\hline Yes & 81 & $59(72.8)$ & Reference & Reference & 48 & $38(79.2)$ & $1.11(0.54-2.28)$ & $1.19(0.56-2.55)$ \\
\hline No & 960 & $742(77.3)$ & $1.27(0.76-2.12)$ & $1.63(0.95-2.79)$ & 585 & $453(77.4)$ & Reference & Reference \\
\hline \multicolumn{5}{|l|}{ Dyslipidemia } & \multicolumn{4}{|c|}{ Hypertension } \\
\hline Yes & 530 & $410(77.4)$ & $1.09(0.81-1.47)$ & $1.01(0.73-1.38)$ & 530 & $408(77.0)$ & Reference & Reference \\
\hline No & 426 & $323(75.8)$ & Reference & Reference & 105 & $85(81.0)$ & $1.27(0.75-2.15)$ & $1.32(0.75-2.31)$ \\
\hline \multicolumn{9}{|l|}{ Study } \\
\hline GNHIES98 & 228 & $195(85.5)$ & Reference & Reference & 155 & $135(87.1)$ & Reference & Reference \\
\hline CARLA & 155 & $114(73.6)$ & $0.47(0.28-0.79)$ & $0.49(0.29-0.83)$ & 84 & $52(61.9)$ & $0.24(0.13-0.46)$ & $0.21(0.11-0.40)$ \\
\hline DHS & 73 & $63(86.3)$ & $1.07(0.50-2.29)$ & $1.10(0.51-2.39)$ & - & - & - & - \\
\hline KORA & 114 & $86(75.4)$ & $0.52(0.30-0.91)$ & $0.57(0.32-1.02)$ & 80 & $63(78.8)$ & $0.55(0.27-1.12)$ & $0.52(0.25-1.07)$ \\
\hline
\end{tabular}




\begin{tabular}{|c|c|c|c|c|c|c|c|c|}
\hline HNR & 263 & $172(65.4)$ & $0.32(0.20-0.50)$ & $0.30(0.19-0.47)$ & 174 & $128(73.6)$ & $0.41(0.23-0.74)$ & $0.38(0.21-0.69)$ \\
\hline SHIP & 215 & $178(82.8)$ & $0.81(0.49-1.36)$ & $0.84(0.50-1.41)$ & 143 & $115(80.4)$ & $0.61(0.33-1.14)$ & $0.63(0.33-1.20)$ \\
\hline
\end{tabular}

Uncontrolled hypertension - Sex, BMI, Study: ROC $=0.68$, Hosmer-Lemeshow p-value $=0.78$.

Uncontrolled dyslipidemia - Sex, MI, Study: $\mathrm{ROC}=0.69$, Hosmer-Lemeshow p-value $=0.96$.

${ }^{*} \mathrm{BP}>=140 / 90 \mathrm{~mm} \mathrm{Hg}$.

$\wedge$ ratio total cholesterol/HDL cholesterol $>=5$.

with known gender differences concerning health behaviour. Especially in the age group of about 30 to 60 years, men use health care services less than women and tend to undervalue health care and health behaviour [31,32]. Several authors hypothesize that societally dominant 'traditional masculinity' leads men to adopt beliefs and behaviours that increase health risks and support the ideal of the 'bulletproof superhero' who would be embarrassed to check his cholesterol level [33-35].

\section{Influence of age}

Findings on the influence of age on hypertension control are controversial (e.g. [36,37]). An explanation for less control with simultaneously intensified treatment, as seen in our study, might be that resistant hypertension occurs more often in older persons [38]. Accordingly, this association was not detected for dyslipidemia. A cross-sectional study in Sweden examined the assumption that the excess cardiovascular risk of persons with diabetes compared to persons without diabetes decreases with increasing age. However, the authors found that the burden of CVD risk factors clustered over the entire life span with increasing glucometabolic disturbance, especially in older women. Likewise, self-rated health decreased with increasing cardio-metabolic risk and age. The authors suggest that a decreased burden of risk in older patients with diabetes might be due to a survival bias [39].

\section{Association with body mass index}

In our study obese participants $(B M I \geq 30 \quad \mathrm{~kg} / \mathrm{m} 2)$ received medication more frequently and were more often well treated for hypertension, although they were more often affected with hypertension than leaner individuals (data not shown). A Swedish population-based study in hypertensive 60-year-old persons with and without diabetes by Carlsson et al. found an inverse, direct association of high waist circumference with uncontrolled hypertension [40]. The same seems to be true for patients in primary care irrespective of diabetes status [41]. Bramlage et al. found that the odds of good blood pressure control in diagnosed and treated individuals was significantly smaller in overweight and obese primary care patients than in patients with normal weight. Using data of physician diagnosed hypertensive DIABCORE participants without diabetes $(n=5012)$, we found that $29.2 \%$ of those with $\mathrm{BMI}<25$ had controlled hypertension (41.2\% were uncontrolled and $29.6 \%$ untreated) compared to $28.6 \%$ of those with $\mathrm{BMI} \geq 30$ (50.9\% uncontrolled and $20.5 \%$ untreated). These results indicate that obese people may be more difficult to treat and obtain goal blood pressure than lean persons; however, they appear to be more aware of their disease. The same seems to be true for a comparison of hypertensive people with and without T2D. Those with T2D are more often treated and well-controlled, much more often treated but not controlled, half as often untreated and half as often unrecognized, irrespective of BMI group (data not shown) than those without T2D. All in all, obese individuals do more often present with a blood pressure $\geq 140 / 90 \mathrm{mmHg}$, irrespective of treatment. Thus, people with additional risk factors (such as obesity and diabetes) may be more aware of their blood pressure and more often treated but at the same time, they are more difficult to effectively treat.

\section{Effect of socio-economic differences}

We expected to find a significant negative association of high socio-economic status with uncontrolled comorbidities, however no significant associations were observed with any socio-economic characteristics and the outcome variables. This might, in the case of school education, be due to the unequal frequencies of low (about $80 \%$ ) vs. high and middle status, which owns to the high mean age of the study population (63 years) and the fact that older people mostly attended junior high school only. In the previously mentioned Swedish study, lack of health care due to low income was independently associated with uncontrolled hypertension in men $(\mathrm{OR}=2.71,95 \% \mathrm{CI} 1.09-6.78)$ but not in women. In contrast, living in an apartment instead of a house (as an indicator of lower socio-economic status) remained a significantly protective factor in an adjusted model in women $(\mathrm{OR}=0.55,95 \% \mathrm{CI} 0.35-0.85)$. The authors stated that the finding was puzzling and offered no explanation [40].

\section{Association with previous cardiovascular disease}

Carlsson et al. confirmed that previous cardiovascular disease or coronary heart disease has a protective effect on uncontrolled hypertension, probably because of more 
Table 5 Factors associated with absent pharmacotherapy in diabetic study participants with concomitant (diagnosed or unrecognized) hypertension or dyslipidemia

\begin{tabular}{|c|c|c|c|c|c|c|c|c|}
\hline & & Hypertension & & & & Dyslipidemia & & \\
\hline & $\mathbf{N}$ & $\begin{array}{c}\text { Without } \\
\text { anti-hypertensive } \\
\text { medication } \mathrm{n}(\%)\end{array}$ & Unadjusted & $\begin{array}{c}\text { Adjusted for } \\
\text { Age, Sex, BMI, } \\
\text { MI, Stroke, Study }\end{array}$ & $\mathbf{N}$ & $\begin{array}{c}\text { Without } \\
\text { lipid lowering } \\
\text { medication } \mathrm{n}(\%)\end{array}$ & Unadjusted & $\begin{array}{l}\text { Adjusted for } \\
\text { Sex, MI }\end{array}$ \\
\hline & 1048 & $226(21.6)$ & OR $(95 \% \mathrm{Cl})$ & OR $(95 \% \mathrm{Cl})$ & 636 & $396(62.3)$ & OR $(95 \% \mathrm{Cl})$ & OR $(95 \% \mathrm{Cl})$ \\
\hline Age in years & & & & & & & & \\
\hline 70-74 & 257 & $38(14.8)$ & Reference & Reference & 134 & $84(62.7)$ & Reference & Reference \\
\hline $65-69$ & 252 & 49 (19.4) & $1.39(0.87-2.21)$ & $1.35(0.83-2.19)$ & 146 & $81(55.5)$ & $0.74(0.46-1.20)$ & $0.71(0.43-1.16)$ \\
\hline $60-64$ & 254 & $57(22.4)$ & $1.67(1.06-2.62)$ & $1.46(0.90-2.35)$ & 157 & 97 (61.8) & $0.96(0.60-1.55)$ & $0.94(0.57-1.54)$ \\
\hline $55-59$ & 151 & $41(27.2)$ & $2.15(1.31-3.53)$ & $1.80(1.06-3.05)$ & 98 & $63(64.3)$ & $1.07(0.62-1.84)$ & $0.93(0.53-1.63)$ \\
\hline $45-54$ & 134 & 41 (30.6) & $2.54(1.54-4.20)$ & $2.28(1.34-3.90)$ & 101 & $71(70.3)$ & $1.41(0.81-2.45)$ & $1.10(0.62-1.95)$ \\
\hline Sex & & & & & & & & \\
\hline Male & 563 & $153(27.2)$ & $2.11(1.54-2.87)$ & $2.11(1.52-2.93)$ & 362 & $246(68.0)$ & $1.75(1.27-2.43)$ & $2.02(1.44-2.84)$ \\
\hline Female & 485 & $73(15.1)$ & Reference & Reference & 274 & $150(54.7)$ & Reference & Reference \\
\hline Smoking & & & & & & & & \\
\hline Yes & 150 & $46(30.7)$ & $1.80(1.22-2.64)$ & $1.40(0.92-2.13)$ & 115 & $80(69.6)$ & $1.49(0.96-2.30)$ & $1.30(0.82-2.04)$ \\
\hline No & 880 & $174(19.8)$ & Reference & Reference & 510 & 309 (60.6) & Reference & Reference \\
\hline BMI & & & & & & & & \\
\hline$>=30$ & 546 & 86 (15.8) & Reference & Reference & 322 & 199 (61.8) & Reference & Reference \\
\hline$<30$ & 500 & $139(27.8)$ & $2.06(1.52-2.79)$ & $1.98(1.43-2.74)$ & 312 & $195(62.5)$ & $1.03(0.75-1.42)$ & $0.89(0.63-1.24)$ \\
\hline Physical inactivit & & & & & & & & \\
\hline Yes & 757 & $160(21.1)$ & Reference & Reference & 461 & $298(64.6)$ & $1.42(0.99-2.04)$ & $1.49(1.03-2.17)$ \\
\hline No & 280 & $64(22.9)$ & $1.11(0.80-1.54)$ & $1.10(0.77-1.56)$ & 167 & $94(56.3)$ & Reference & Reference \\
\hline School education & & & & & & & & \\
\hline Low & 811 & $168(20.7)$ & Reference & Reference & 499 & $308(61.7)$ & Reference & Reference \\
\hline High and middle & 221 & $54(24.4)$ & $1.24(0.87-1.76)$ & $1.08(0.74-1.58)$ & 126 & $82(65.1)$ & $1.16(0.77-1.74)$ & $0.98(0.64-1.50)$ \\
\hline Income & & & & & & & & \\
\hline Low & 162 & $37(22.8)$ & Reference & Reference & 104 & $65(62.5)$ & Reference & Reference \\
\hline Middle & 674 & $133(19.7)$ & $0.83(0.55-1.26)$ & $0.73(0.47-1.14)$ & 405 & $248(61.2)$ & $0.95(0.61-1.48)$ & $0.92(0.58-1.47)$ \\
\hline High & 109 & $31(28.4)$ & $1.34(0.77-2.34)$ & $0.90(0.49-1.65)$ & 62 & $45(72.6)$ & $1.59(0.80-3.15)$ & $1.17(0.57-2.39)$ \\
\hline Myocardial infarc & ction & & & & & & & \\
\hline Yes & 107 & $8(7.5)$ & Reference & Reference & 89 & $34(38.2)$ & Reference & Reference \\
\hline No & 934 & $217(23.2)$ & $3.75(1.79-7.82)$ & $3.65(1.72-7.75)$ & 540 & $357(66.1)$ & $3.16(1.99-5.01)$ & $3.62(2.25-5.82)$ \\
\hline Stroke & & & & & & & & \\
\hline Yes & 81 & 7 (8.6) & Reference & Reference & 48 & $29(60.4)$ & Reference & Reference \\
\hline No & 960 & 219 (22.8) & $3.12(1.42-6.88)$ & $3.45(1.53-7.79)$ & 585 & $366(62.6)$ & $1.10(0.60-2.00)$ & $0.99(0.52-1.85)$ \\
\hline Dyslipidemia & & & & & Hype & ertension & & \\
\hline Yes & 530 & 109 (20.6) & Reference & Reference & 530 & $322(60.8)$ & Reference & Reference \\
\hline No & 426 & 97 (22.8) & $1.14(0.84-1.55)$ & $1.15(0.83-1.60)$ & 105 & $74(70.5)$ & $1.54(0.98-2.43)$ & $1.71(1.06-2.78)$ \\
\hline Study & & & & & & & & \\
\hline GNHIES98 & 228 & $65(28.5)$ & Reference & Reference & 155 & $102(65.8)$ & Reference & Reference \\
\hline CARLA & 155 & $22(14.2)$ & $0.42(0.24-0.71)$ & $0.39(0.22-0.69)$ & 84 & $46(54.8)$ & $0.63(0.37-1.08)$ & $0.56(0.32-0.98)$ \\
\hline DHS & 73 & $17(23.3)$ & $0.76(0.41-1.41)$ & $0.91(0.47-1.74)$ & - & - & - & - \\
\hline KORA & 114 & $24(21.1)$ & $0.67(0.39-1.14)$ & $0.82(0.46-1.45)$ & 80 & $52(65.0)$ & $0.97(0.55-1.70)$ & $0.95(0.53-1.72)$ \\
\hline HNR & 263 & $51(19.4)$ & $0.60(0.40-0.92)$ & $0.60(0.39-0.93)$ & 174 & $101(58.1)$ & $0.72(0.46-1.13)$ & $0.68(0.42-1.08)$ \\
\hline
\end{tabular}


Table 5 Factors associated with absent pharmacotherapy in diabetic study participants with concomitant (diagnosed or unrecognized) hypertension or dyslipidemia (Continued)

\begin{tabular}{lllllllll}
\hline SHIP & 215 & $47(21.9)$ & $0.70(0.46-1.08)$ & $0.73(0.46-1.16)$ & 143 & $95(66.4)$ & $1.03(0.64-1.66)$ & $1.08(0.65-1.79)$
\end{tabular}

No pharmacotherapy for hypertension - Age, Sex, BMI, MI, Stroke, Study: ROC $=0.71$, Hosmer-Lemeshow $p$-value $=0.46$.

No pharmacotherapy for dyslipidemia - Sex, MI: ROC $=0.64$, Hosmer-Lemeshow $p$-value $=0.62$.

intense treatment, better medication adherence and/or symptom relief of angina pectoris [40].

\section{Influence of more complex factors}

There are a number of possible influences on uncontrolled hypertension and dyslipidemia that we could not consider. For example, the Swedish study by Carlsson et al. included data on nutrition and found that daily intake of fruit had an independent, protective effect in men but not in women [40].

Steckelings, 2004 et al. [5] used data from primary care patients, irrespective of diabetes status (the HYDRA Study: Hypertension and Diabetes Screening and Awareness Study), to describe possible determinants of unsatisfactory hypertension control in Germany. Less than 30\% of treated and $19 \%$ of all patients, treated or untreated, had controlled blood pressure $<140 / 90 \mathrm{mmHg}$. The frequency of diagnosis was particularly low in young people, probably due to insufficient blood pressure screening. The authors found that physicians used outdated guidelines and based treatment on diastolic pressure. The great majority of participants $(94 \%)$ stated that they knew that hypertension is an important risk factor for serious diseases, and most of them (63\%) occasionally measured their own blood pressure. However, the physicians participating in the study often misclassified their patients as 'well controlled' even though they had BP measurements $\geq 140 / 90 \mathrm{mmHg}$.

According to a review by Düsing et al. 2006 [42], more complex, hindering factors could also be insufficient education and motivation provided to the patient by physicians, patients' reluctance to change lifestyle factors or commence/modify drug treatment, lack of awareness of the risks associated with hypertension, and poor compliance. The latter is a complex and thoroughly explored concept and challenge (e.g. [43]). Apparently, many people with hypertension do not seem to recognize high blood pressure as a progressive chronic illness, but rather misinterpret it as a risk factor in a gamble with a potentially positive outcome $[44,45]$.

Finally, the sex of the attending physician has been shown to play a role in the quality of risk factor control in patients with hypertension and dyslipidemia. In a cross-sectional study by Journath et al., diabetic men and women achieved goals for blood pressure control, and men achieved goals for cholesterol control more often if they were treated by female physicians [46].
Likewise, a German study including 51,053 diabetes patients treated by 3,096 physicians concluded that female physicians achieved a better quality of care than their male counterparts, especially in risk management important for future disease prognosis [47].

\section{Differences between Europe and the United States/ Canada}

Interestingly, there appears to be an intriguing difference in hypertension prevalence and control, irrespective of diabetes status, between Europe and the United States/ Canada that has not been appreciated and examined sufficiently. Wolf-Maier et al. [48,49] compared sample surveys conducted in the 1990s in Germany, Finland, Sweden, England, Spain, Italy, Canada, and the United States and found that even though mean BMI was very similar across these countries, the prevalence of hypertension, defined as blood pressure $>140 / 90 \mathrm{mmHg}$ or intake of anti-hypertensive medication, differed remarkably. The European average was $44.2 \%$ compared with $27.6 \%$ in North America. Germany had the highest prevalence with 55.3\% [48]. Treatment and control of hypertensive participants within the individual studies was also significantly better in the United States than in Europe with 7.8\% hypertension control in the population $(29.9 \%$ in treated hypertensive participants) in Germany compared to $28.6 \%$ (54.5\% in treated hypertensives) in the United States [49].

In order to improve awareness, creative new approaches have been successfully implemented in the United States, e.g. by addressing the issue and counseling black men during a visit at a barbershop [50]. Such innovative ideas might also work in Germany - possibly for younger men with diabetes and no previous cardiovascular complications.

\section{Conclusions}

In the DIAB-CORE study, participants with diabetes who were at the greatest odds of uncontrolled comorbidities and no pharmacotherapy were male, younger, had lower BMI and no history of cardiovascular disease. Although the general risk profile appears relatively low, preventative efforts should not overlook, but specifically consider this group of patients.

\section{Abbreviations}

ATC: Anatomical Therapeutic Chemical Classification System; BMI: Body mass index; BP: Blood pressure; CARLA: Cardiovascular Disease Living and Ageing Study; CVD: Cardiovascular disease; DHS: Dortmund Health Study;

DMP: Disease management program; GNHIES98: German National Health 
Interview and Examination Survey; HDL: High-density lipoprotein; KORA: Cooperative Health Research in the Region of Augsburg Study; LDL: Low-density lipoprotein; OAD: Oral anti-diabetic medication; HNR: Heinz Nixdorf-Recall Risk Factors Evaluation of Coronary Calcification and Lifestyle Study; SD: Standard deviation; SHIP: Study of Health in Pomerania; T2D: Type 2 diabetes; TC: Total cholesterol.

\section{Competing interests}

The authors declare that they have no competing interests.

\section{Authors' contributions}

I-MR performed the statistical analyses and wrote the manuscript. CM and WM worked on pooling of the data, contributed to the discussion and reviewed/edited the manuscript. AM contributed to the discussion and reviewed/edited the manuscript. $\Pi$ and WR worked on pooling of the data and reviewed/edited the manuscript. SS, HV, AK, K-HG, KB, GM, UE, HN, SM and SA contributed data and reviewed/edited the manuscript. All authors read and approved the final manuscript.

\section{Acknowledgements}

We thank the investigative groups of all individual studies, the study staffs and all study participants.

This work was supported by 'Kompetenznetz Diabetes mellitus (Competence Network for Diabetes mellitus)' funded by the Federal Ministry of Education and Research (FKZ 01GI0814-0816/-0855-0858).

The KORA research platform (KORA, Cooperative Health Research in the Region of Augsburg) was initiated and financed by the Helmholtz Zentrum München - German Research Center for Environmental Health, which is funded by the German Federal Ministry of Education and Research and by the State of Bavaria.

The CARLA study was funded by a grant from the Deutsche

Forschungsgemeinschaft as part of the Collaborative Research Center 598 'Heart failure in the elderly - cellular mechanisms and therapy' at the Medical Faculty of the Martin-Luther-University Halle-Wittenberg, by a grant from the Wilhelm-Roux Programme of the Martin-Luther-University HalleWittenberg, by the Ministry of Education and Cultural Affairs of SaxonyAnhalt and by the Federal Employment Office.

SHIP is part of the Community Medicine Research net (http://www. community-medicine.de) at the University of Greifswald, Germany. Funding was provided by grants from the German Federal Ministry of Education and Research (BMBF, grant 01ZZ0403), the Ministry for Education, Research and Cultural Affairs and the Ministry for Social Affairs of the Federal State of Mecklenburg-West Pomerania.

The collection of socio-demographic and clinical data in the Dortmund Health Study (DHS) was supported by the German Migraine \& Headache Society (DMKG) and by unrestricted grants in equal shares from Astra Zeneca, Berlin Chemie, Boots Healthcare, Glaxo-Smith-Kline, McNeil Pharma (formerly Woelm Pharma), MSD Sharp \& Dohme and Pfizer to the University of Muenster.

The German National Health Interview and Examination Survey (GNHIES98) was funded by the German Ministry of Health.

The Heinz Nixdorf Recall Study (HNR) was supported by institutional funding (German Diabetes Centre) of the German Ministry of Health and by the Ministry of Science of North-Rhine Westphalia. It was further funded by the German Ministry of Education and Research as part of the Diabetes Competence Network. We thank the Heinz Nixdorf Foundation (Chairman: Dr jur. G. Schmidt) for the generous support of the Heinz Nixdorf Recall Study. The study is also supported by the German Ministry of Education and Science.

\section{Author details}

${ }^{1}$ Institute of Epidemiology II, Helmholtz Zentrum München, German Research Center for Environmental Health $(\mathrm{GmbH})$ and German Center for Diabetes Research (DZD e.V.), Ingolstädter Landstrasse 1, D-85764 München/ Neuherberg, Germany. ${ }^{2}$ Institute of Health Economics and Health Care Management, Helmholtz Zentrum München, German Research Center for Environmental Health $(\mathrm{GmbH})$, Neuherberg, Germany. ${ }^{3}$ Institute for Community Medicine, University Medicine Greifswald, Greifswald, Germany. ${ }^{4}$ Institute of Medical Epidemiology, Biostatistics and Informatics, Martin-Luther-University Halle-Wittenberg, Halle, Saale, Germany. ${ }^{5}$ German Cancer Research Centre, Division of Cancer Epidemiology, Heidelberg,
Germany. ${ }^{6}$ Institute of Epidemiology and Social Medicine, University of Muenster, Muenster, Germany. ${ }^{7}$ Department of Epidemiology and Health Reporting, Robert-Koch-Institute, Berlin, Germany. ${ }^{8}$ Institute of Biometrics and Epidemiology, German Diabetes Center, Leibniz Center for Diabetes, Research at Heinrich-Heine-University Düsseldorf, Düsseldorf, Germany. ${ }^{9}$ Institute of Medical Informatics, Biometry and Epidemiology, University Hospital of Essen, University of Duisburg-Essen, Essen, Germany. ${ }^{10}$ MONICA/KORA Myocardial Infarction Registry, Central Hospital of Augsburg, Augsburg, Germany.

Received: 24 July 2012 Accepted: 1 October 2012

Published: 5 October 2012

\section{References}

1. Association AD: Standards of medical care in diabetes-2011. Diabetes Care 2011, 34(Suppl 1):S11-S61.

2. Berry J, Keebler ME, McGuire DK: Diabetes mellitus and cardiovascular disease. Pandora's box has been opened. Herz 2004, 29:456-462.

3. Mancia G: The association of hypertension and diabetes: prevalence, cardiovascular risk and protection by blood pressure reduction. Acta Diabetol 2005, 42(Suppl 1):S17-S25.

4. Scott R, Donoghoe M, Watts GF, O'Brien R, Pardy C, Taskinen MR, Davis TM, Colman PG, Manning P, Fulcher G, Keech AC: Impact of metabolic syndrome and its components on cardiovascular disease event rates in 4900 patients with type 2 diabetes assigned to placebo in the FIELD randomised trial. Cardiovasc Diabetol 2011, 10:102

5. Steckelings UM, Stoppelhaar M, Sharma AM, Wittchen HU, Krause P, Kupper B, Kirch W, Pittrow D, Ritz E, Goke B, et al: HYDRA: possible determinants of unsatisfactory hypertension control in German primary care patients. Blood Press 2004, 13:80-88.

6. Gasse C, Hense HW, Stieber J, Doring A, Liese AD, Keil U: Assessing hypertension management in the community: trends of prevalence, detection, treatment, and control of hypertension in the MONICA Project, Augsburg 1984-1995. J Hum Hypertens 2001, 15:27-36.

7. Meisinger $\mathrm{C}$, Heier M, Völzke H, Lowel H, Mitusch R, Hense HW, Ludemann $J$ : Regional disparities of hypertension prevalence and management within Germany. J Hypertens 2006, 24:293-299.

8. Rückert IM, Schunk M, Holle R, Schipf S, Völzke H, Kluttig A, Greiser KH, Berger K, Müller G, Ellert U, et al: Blood pressure and lipid management fall far short in persons with type 2 diabetes: Results from the DIAB-CORE Consortium including six German population-based studies. Cardiovasc Diabetol 2012, 11:50.

9. Raum E, Lietzau S, Stegmaier C, Brenner H, Rothenbacher D: For the majority of patients with diabetes blood pressure and lipid management is not in line with recommendations. Results from a large populationbased cohort in Germany. Pharmacoepidemiol Drug Saf 2008, 17:485-494.

10. Schunk M, Stark R, Reitmeir P, Rathmann W, Meisinger C, Holle R: [Improvements in type 2 diabetes care? Pooled analysis of survey data in southern Germany (KORA) from 1999-2008]. Bundesgesundheitsblatt Gesundheitsforschung Gesundheitsschutz 2011, 54:1187-1196.

11. Sharma AM, Wittchen HU, Kirch W, Pittrow D, Ritz E, Goke B, Lehnert H, Tschope D, Krause P, Hofler M, et al: High prevalence and poor control of hypertension in primary care: cross-sectional study. J Hypertens 2004, 22:479-486

12. Stark RG, Schunk MV, Meisinger C, Rathmann W, Leidl R, Holle R: Medical care of type 2 diabetes in German disease management programmes: a population-based evaluation. Diabetes Metab Res Rev 2011, 27:383-391.

13. Steinhagen-Thiessen $E$, Bramlage $P$, Losch $C$, Hauner $H$, Schunkert $H$, Vogt $A$, Wasem J, Jockel KH, Moebus S: Dyslipidemia in primary care-prevalence, recognition, treatment and control: data from the German Metabolic and Cardiovascular Risk Project (GEMCAS). Cardiovasc Diabetol 2008, 7:31

14. Vennemann MM, Hummel T, Berger K: The association between smoking and smell and taste impairment in the general population. J Neurol 2008, 255:1121-1126.

15. Rathmann W, Haastert B, Icks A, Lowel H, Meisinger C, Holle R, Giani G: High prevalence of undiagnosed diabetes mellitus in Southern Germany: target populations for efficient screening. The KORA survey 2000. Diabetologia 2003, 46:182-189.

16. Greiser KH, Kluttig A, Schumann B, Kors JA, Swenne CA, Kuss O, Werdan K, Haerting J: Cardiovascular disease, risk factors and heart rate variability in the elderly general population: design and objectives of the 
CARdiovascular disease, Living and Ageing in Halle (CARLA) Study. BMC Cardiovasc Disord 2005, 5:33.

17. Völzke H, Alte D, Schmidt CO, Radke D, Lorbeer R, Friedrich N, Aumann N, Lau K, Piontek M, Born G, et al: Cohort profile: the study of health in Pomerania. Int J Epidemiol 2011, 40:294-307.

18. Bellach BM, Knopf H, Thefeld W: The German Health Survey. 1997/98. Gesundheitswesen 1998, 60(Suppl 2):S59-S68.

19. Neuhauser HK, Ellert U, Kurth BM: A comparison of Framingham and SCORE-based cardiovascular risk estimates in participants of the German National Health Interview and Examination Survey 1998. Eur J CardiovasC Prev Rehabil 2005, 12:442-450.

20. Schmermund A, Mohlenkamp S, Stang A, Gronemeyer D, Seibel R, Hirche H, Mann K, Siffert W, Lauterbach K, Siegrist J, et al: Assessment of clinically silent atherosclerotic disease and established and novel risk factors for predicting myocardial infarction and cardiac death in healthy middle-aged subjects: rationale and design of the Heinz Nixdorf RECALL Study. Risk Factors, Evaluation of Coronary Calcium and Lifestyle. Am Heart J 2002, 144:212-218.

21. Kinosian B, Glick H, Garland G: Cholesterol and coronary heart disease: predicting risks by levels and ratios. Ann Intern Med 1994, 121:641-647.

22. Meisinger $\mathrm{C}$, Loewel $\mathrm{H}$, Mraz W, Koenig W: Prognostic value of apolipoprotein $B$ and $A-I$ in the prediction of myocardial infarction in middle-aged men and women: results from the MONICA/KORA Augsburg cohort study. Eur Heart J 2005, 26:271-278.

23. Mielck A, Kiess R, von dem Knesebeck O, Stirbu I, Kunst AE: Association between forgone care and household income among the elderly in five Western European countries - analyses based on survey data from the SHARE-study. BMC Health Serv Res 2009, 9:52.

24. McLean DL, Simpson SH, McAlister FA, Tsuyuki RT: Treatment and blood pressure control in 47,964 people with diabetes and hypertension: a systematic review of observational studies. Can J Cardiol 2006, 22:855-860.

25. Kautzky-Willer A, Kamyar MR, Gerhat D, Handisurya A, Stemer G, Hudson S, Luger A, Lemmens-Gruber R: Sex-specific differences in metabolic control, cardiovascular risk, and interventions in patients with type 2 diabetes mellitus. Gend Med 2010, 7:571-583.

26. Ferrara A, Mangione CM, Kim C, Marrero DG, Curb D, Stevens M, Selby JV: Sex disparities in control and treatment of modifiable cardiovascular disease risk factors among patients with diabetes: Translating Research Into Action for Diabetes (TRIAD) Study. Diabetes Care 2008, 31:69-74

27. Winston GJ, Barr RG, Carrasquillo O, Bertoni AG, Shea S: Sex and racial/ ethnic differences in cardiovascular disease risk factor treatment and control among individuals with diabetes in the Multi-Ethnic Study of Atherosclerosis (MESA). Diabetes Care 2009, 32:1467-1469.

28. Gouni-Berthold I, Berthold HK, Mantzoros CS, Bohm M, Krone W: Sex disparities in the treatment and control of cardiovascular risk factors in type 2 diabetes. Diabetes Care 2008, 31:1389-1391.

29. Gobl CS, Brannath W, Bozkurt L, Handisurya A, Anderwald C, Luger A, Krebs M, Kautzky-Willer A, Bischof MG: Sex-specific differences in glycemic control and cardiovascular risk factors in older patients with insulintreated type 2 diabetes mellitus. Gend Med 2010, 7:593-599.

30. Sekerija M, Poljicanin T, Erjavec K, Liberati-Cizmek AM, Prasek M, Metelko Z: Gender differences in the control of cardiovascular risk factors in patients with type 2 diabetes -a cross-sectional study. Intern Med 2012, 51:161-166

31. Lademann J, Kolip P: Schwerpunktbericht der Gesundheitsberichterstattung des Bundes - Gesundheit von Frauen und Männern im mittleren Lebensalter. Berlin: Robert Koch-Institut; 2005.

32. Pinkhasov RM, Wong J, Kashanian J, Lee M, Samadi DB, Pinkhasov MM, Shabsigh R: Are men shortchanged on health? Perspective on health care utilization and health risk behavior in men and women in the United States. Int J Clin Pract 2010, 64:475-487.

33. Courtenay WH: Constructions of masculinity and their influence on men's well-being: a theory of gender and health. Soc Sci Med 2000, 50:1385-1401.

34. Galdas PM, Cheater F, Marshall P: Men and health help-seeking behaviour: literature review. J Adv Nurs 2005, 49:616-623.

35. McVittie C, Willock J: "You can't fight windmills": how older men do health, ill health, and masculinities. Qual Health Res 2006, 16:788-801.

36. Cushman WC, Ford CE, Cutler JA, Margolis KL, Davis BR, Grimm RH, Black $\mathrm{HR}$, Hamilton BP, Holland J, Nwachuku C, et al: Success and predictors of blood pressure control in diverse North American settings: the antihypertensive and lipid-lowering treatment to prevent heart attack trial (ALLHAT). J Clin Hypertens (Greenwich) 2002, 4:393-404

37. Egan BM, Zhao $Y$, Axon RN: US trends in prevalence, awareness, treatment, and control of hypertension, 1988-2008. JAMA 2010, 303:2043-2050.

38. Calhoun DA, Jones D, Textor S, Goff DC, Murphy TP, Toto RD, White A, Cushman WC, White W, Sica D, et al: Resistant hypertension: diagnosis, evaluation, and treatment: a scientific statement from the American Heart Association Professional Education Committee of the Council for High Blood Pressure Research. Circulation 2008, 117:e510-e526.

39. Leosdottir M, Willenheimer R, Persson M, Nilsson PM: The association between glucometabolic disturbances, traditional cardiovascular risk factors and self-rated health by age and gender: a cross-sectional analysis within the Malmo Preventive Project. Cardiovasc Diabetol 2011, 10:118.

40. Carlsson AC, Wandell PE, Journath G, de Faire U, Hellenius ML: Factors associated with uncontrolled hypertension and cardiovascular risk in hypertensive 60-year-old men and women-a population-based study. Hypertens Res 2009, 32:780-785.

41. Bramlage P, Pittrow D, Wittchen HU, Kirch W, Boehler S, Lehnert H, Hoefler $M$, Unger T, Sharma AM: Hypertension in overweight and obese primary care patients is highly prevalent and poorly controlled. Am J Hypertens 2004, 17:904-910.

42. Dusing R: Overcoming barriers to effective blood pressure control in patients with hypertension. Curr Med Res Opin 2006, 22:1545-1553.

43. Jin J, Sklar GE, Min Sen Oh V, Chuen Li S: Factors affecting therapeutic compliance: A review from the patient's perspective. Ther Clin Risk Manag 2008, 4:269-286.

44. Jokisalo E, Kumpusalo E, Enlund H, Takala J: Patients' perceived problems with hypertension and attitudes towards medical treatment. J Hum Hypertens 2001, 15:755-761.

45. Anthony H, Valinsky L, Inbar Z, Gabriel C, Varda S: Perceptions of hypertension treatment among patients with and without diabetes. BMC Fam Pract 2012, 13:24

46. Journath G, Hellenius ML, Carlsson AC, Wandell PE, Nilsson PM: Physicians' gender is associated with risk factor control in patients on antihypertensive and lipid lowering treatment. Blood Press 2010, 19:240-248

47. Berthold HK, Gouni-Berthold I, Bestehorn KP, Bohm M, Krone W: Physician gender is associated with the quality of type 2 diabetes care. J Intern Med 2008, 264:340-350

48. Wolf-Maier K, Cooper RS, Banegas JR, Giampaoli S, Hense HW, Joffres M, Kastarinen M, Poulter N, Primatesta P, Rodriguez-Artalejo F, et al: Hypertension prevalence and blood pressure levels in 6 European countries, Canada, and the United States. JAMA 2003, 289:2363-2369.

49. Wolf-Maier K, Cooper RS, Kramer H, Banegas JR, Giampaoli S, Joffres MR, Poulter N, Primatesta P, Stegmayr B, Thamm M: Hypertension treatment and control in five European countries, Canada, and the United States. Hypertension 2004, 43:10-17.

50. Victor RG, Ravenell JE, Freeman A, Leonard D, Bhat DG, Shafiq M, Knowles P, Storm JS, Adhikari E, Bibbins-Domingo K, et al: Effectiveness of a barberbased intervention for improving hypertension control in black men: the BARBER-1 study: a cluster randomized trial. Arch Intern Med 2011, 171:342-350.

doi:10.1186/1475-2840-11-120

Cite this article as: Rückert et al:: Personal attributes that influence the adequate management of hypertension and dyslipidemia in patients with type 2 diabetes. Results from the DIAB-CORE Cooperation. Cardiovascular Diabetology 2012 11:120. 